\title{
How to Improve Teaching Efficiency of University Vocal Music Course
}

\author{
Jindong Zhang \\ Hubei Normal University, Huangshi Hubei, 435002, China
}

Keywords: University, Vocal music course,Teaching efficiency, Improving strategy.

\begin{abstract}
In university vocal music teaching, teachers must pay attention to teaching efficiency and teaching quality improvement, mainly because university vocal music teaching efficiency directly determines students' studying quality, based on this, during teaching, university vocal music teachers have to innovate their own teaching method, make complete teaching plan, take effective measures to stimulate students' study interest, cultivate students' vocal music skill, on the basis of optimizing students' studying system to improve university vocal music course teaching efficiency and help it develop in a better direction.
\end{abstract}

\section{Introduction}

At present, there are still a lot of deficiencies in university vocal music course teaching, it cannot positively guide students to learn vocal music knowledge, cannot construct scientific art education frame, which has an adverse influence, therefore, in practical university vocal music teaching, teachers must pay attention to students' comprehensive ability, teachers' teaching ability, under the situation of integrating advance teaching system to cultivate students' vocal music quality, further to improve university vocal music teaching efficiency to lay a solid foundation for students' later development.

\section{Problems of university vocal music teaching}

Since the reform and opening up, China's art teaching development obtained great achievement, among which, university vocal music teaching aroused wide attention, our country also give some policy support. However, in current university vocal music teaching, there are still many deficiencies, no matter teaching method or teaching tools are lack behind, which make it hard to improve teaching efficiency and caused bad effect. Specifically include following points:

First of all, vocal teaching course is boring. Curriculum has direct relation with teaching efficiency, only optimizing curriculum and completing teaching content can improve teaching efficiency. However, though major of university vocal music teachers have set up teaching pattern, but in practical training, only single course can be used, which cannot express the diversity of vocal teaching. Meanwhile, university vocal music teaching is limited in all kinds of vocal music works and skills, teachers cannot positively introduce in other teaching content, which cause difficult problems for students in vocal music learning and cause adverse influence.

Secondly, the teaching goal of university vocal music is not clear. Currently, many university vocal music teachers did not make clear their teaching goals in teaching process, only can implement teaching work according to vocal music teaching materials, cannot teach students in accordance of their aptitude, which cause bad effect on students' development. Meanwhile, part of teachers only can cultivate students' vocal music performance and singing skills, cannot improve students' aesthetic ability, cannot set diverse elements in teaching content, thus not only can reduce students' learning activity, but also hard to improve teaching efficiency. 
Secondly, teaching content is broken away from real life. Influenced by traditional teaching concept, many university vocal music teachers set diverse teaching content in their teaching process, cannot make teaching plan according to students' real need, which caused low efficiency. Meanwhile, part of university vocal music teachers neglect the connection with teaching content and real life, they cannot cultivate students' ability to solve problems in real life, cannot improve students application ability which is difficult to improve learning quality.

At last, students' studying method is not suitable. In university vocal music teaching process, part of students did not form good studying habit, cannot summarize vocal music knowledge to improve learning efficiency, cannot analyze relevant problems and improve learning ability. Meanwhile, many students cannot apply knowledge into real life, and hard to summarize live and learning experience in failure, when face difficulty, they have no good psychology to deal with it but just escape, which caused an adverse influence, this also make university vocal music teachers cannot improve teaching efficiency. If university vocal music teachers and students cannot realize the seriousness of this kind of problems, cannot take effective measures to solve problems, this will affect students' vocal music quality development and teachers' teaching efficiency improvement.

\section{The importance of improving university vocal music curriculum teaching efficiency}

Because there are still many deficiencies in China's university vocal music curriculum, vocal music teaching efficiency is low, which cannot improve students' study quality and is hard to cultivate professional talents, therefore, improving university vocal music teaching efficiency has an decisive effect on students' and teachers' development. Firstly, improving university vocal music teaching efficiency can optimize students' study pattern, guide students to take part in all kinds of teaching activities, cultivate student' independent study ability thus to improve study quality. Secondly, in the process of university vocal music teachers improve teaching efficiency, they will innovate teaching pattern, gradually perfect teaching content and cultivate social need professional vocal music talents according to real social development. Thirdly, after improving teaching efficiency of university vocal music curriculum, students can strengthen their creativity through teachers' guideline, on a certain content, they can perfect students' study system, strengthen students' learning dynamics, meanwhile, students also can summarize their deficiencies in their study and take effective measures to make up for the deficiency to improve their professional ability. At last, in the process of improving university vocal music teaching efficiency, teachers can base on current teaching situation wo carry out communication with students, timely understand students' demand and make perfect teaching strategy to realize individualized teaching to help students grasp relevant knowledge and form their own special vocal music structure, and help students take part in social vocal music works to lay a solid foundation for their future development ${ }^{[1]}$.

\section{Measures to improve university vocal music curriculum teaching efficiency}

In order to improve teaching efficiency, university vocal music teachers should analyze from students, themselves and university to make complete strategy to improve teaching efficiency. Specific measures include following points:

\section{Students}

In the real teaching of university vocal music, teachers have to pay attention to students' study situation and based on students' study demand to make complete teaching measures and ensure improve students' study quality.

Firstly, teachers should guide students to summarize vocal music learning pattern. Every student has their own study habit and features, teachers need to guide them summarize all kinds of study patterns and choose the suitable one. Meanwhile, students should objectively value their own study ability, gradually optimize own study method, on the basis of improving vocal music level to 
optimize university vocal music curriculum teaching pattern, to help students use good study method to learn vocal music knowledge to improve teaching efficiency ${ }^{[2]}$.

Secondly, teachers should guide students to summarize life principles. During university vocal music teaching, teachers should not only teach vocal music knowledge, but also should involve life principles, Ideological and moral knowledge, positively guide students to summarize life principles and ensure students can learn relevant knowledge according to vocal music teaching demand. At this time, teachers can combine life with vocal music knowledge, for example, when teach "I like snowflake from the sky", teachers can interpret the love story to help students fully understand the emotion of this song, ensure students can understand relevant knowledge and help students integrate emotion in vocal music and improve students' experience efficiency.

Thirdly, university vocal music teachers should help students form positive study attitude. When studying vocal music, university students normally will meet all kinds of problems and puzzles, generally speaking, students will escape from these problems and puzzles, which will cause bad effect on their development. Based on this, university vocal music teachers should positively guide students to face difficulties with right attitude. Teachers should summarize failure experience with students and analyze reasons for failure to find suitable solution. Meanwhile, teachers should pay attention to students' grasp on vocal music knowledge and skills, under the situation of improving students' confidence in vocal music to strengthen their study ability to reach teaching effect.

\section{University}

In the vocal music teaching process, university is the main environment for teaching and studying, which has a direct influence on vocal music teaching efficiency, only providing a good environment for students and teachers can effectively improve teaching efficiency.

Firstly, create good teaching and studying environment. In university vocal music studying process, university has set up teaching activities system, however, it prohibits teaching progress on a certain extent. Therefore, university leaders and teachers should create environment goal to ensure a good study environment for students to improve teaching efficiency. In this process, universities can carry out some singing competition and debate competition in the diverse teaching activities, which can stimulate students to improve study enthusiasm. Meanwhile, good teaching and studying environment is helpful teachers to innovate teaching pattern and implement teaching according to students' real demand to improve students' study quality ${ }^{[4]}$.

Secondly, positively introduce in advanced equipment. University vocal music teaching not only needs good environment but also need advanced teaching equipment, such as instrument of vocal music, help students deeply understand relevant knowledge in contact with instrument, therefore, universities should try all kinds of methods to raise fund for instrument and purchase modern vocal music instrument according to students' real demand to optimize teaching pattern. At the same time, universities also should pay attention to the instrument application to help teachers optimize their own teaching pattern and implement teaching work according to students' real demand to lay a solid foundation for students' future development ${ }^{[5]}$.

\section{Teachers}

In the process of university vocal music teaching, teachers' profession quality and teaching skill can directly determine students' study, based on this, university vocal music teachers must pat attention to their own teaching responsibility, ensuring under the equal communication with students to provide better studying suggestion to reach best teaching effect.

First of all, university vocal music teacher should reasonably communicate with students to ensure make complete teaching system according to students' individual development, to improve students' study efficiency, at this time, university vocal music teachers can provide students with self-improvement opportunity, for example, when interpret "The birds are singing in the wind", teachers can divide students into several groups, require students to discuss on this song, after discussion, require students to sing the song by themselves, ensure every student has opportunity to sing, thus can effectively improve students' study efficiency, meanwhile, teachers should analyze 
students' real study situation when they are singing and teach according to their deficiencies to improve teaching efficiency.

Secondly, university vocal music teachers should carry out individual teaching activities to make students get individualized cultivation to improve their study efficiency. For example, in the process of teaching vocal music knowledge, teachers should timely find every student's advantages, and implement targeted teaching according to students' real situation, ensure to display students' strong points to improve teaching efficiency.

Thirdly, university vocal music teachers should innovate teaching pattern, permeate real life information to students, on the basis of extending students' view to guide them grasp basic knowledge and skills of vocal music, on a certain extent, can improve students' study quality. In this process, teachers can use scene to create teaching pattern for students, for example, when interpret "The three gorges, my hometown", teachers can create teaching scene for students then ask students to imagine author's emotion when creating this song, on a certain extent, this can promote students integrate real emotion into vocal music knowledge studying to improve university vocal music teaching efficiency.

Fourthly, teachers should set up the correct model for students, ensure to display model function, no matter on teaching or life aspect, teachers should regulate their own behaviors to guide students form good life habit and study habit, meanwhile, teachers should discuss study strategy with students according to their real situation to optimize students' study system, on the basis of improving students' study quality to cultivate self-study ability to help them develop with the right direction.

\section{Conclusion}

During teaching process, university vocal music teachers must pay attention to the innovation of teaching pattern, ensure to make targeted teaching content and cultivate students' vocal music skills. Meanwhile, university vocal music teachers should pay attention to own professional quality, periodically study professional knowledge and grasp advance teaching skill, devote to cultivating excellent professional vocal music talents in the new period.

\section{References}

[1] Wang Jin. Analysis on the Methods of Improving University Vocal Music Teaching Efficiency, Popular Literature, 2012(13):234.

[2] Zhang Ying. Analysis on How to Improve University Vocal Music Teaching Efficiency, Music Space Time, 2015(16):146.

[3] Li Dongmei. Analysis on Improving University Vocal Music Teaching Efficiency in the New Proid, Northern Music, 2016,36(1):190-190.

[4] Liao Xinglin. Exploration and Practice of Teaching Pattern of University Vocal Music, Theatrical Family, 2015(9):181-182.

[5] Li Li. Thinking on the Innovation of University Vocal Music Education, Literary and artistic life, 2013(4):230-230. 